\title{
土地利用/覆盖变化对陆地生态系统碳循环的影响
}

\author{
陈广生 田汉勤* \\ (美国奥本大学林业与野生生物学院,生态系统与区域研究实验室, 奥本 AL36849, 美国)
}

摘 要 土地利用/覆盖变化是学术界最为关注的环境变化问题之一, 它能够影响陆地生态系统的生物多样性、 水、碳和养分循环、能量平衡, 引起温室气体释放增加等其它环境问题。不同类型的土地利用/覆盖变化对生态系 统碳循环的作用不同, 由高生物量的森林转化为低生物量的草地、农田或城市后, 大量的 $\mathrm{CO}_{2}$ 将释放到大气中。全 球土地利用/覆盖变化具有很强的空间变异性，对生态系统碳循环的影响同样具有明显的空间差异 热带地区的土 地利用/覆盖变化造成大量的碳释放, 而中高纬度地区土地利用/覆盖变化则表现为碳汇。目前, 土地利用/覆盖变 化引起的生态系统碳循环变化主要是通过模型模拟来估算的。尽管土地利用/覆盖变化及其相关过程与生态系统 碳循环的关系已经比较清楚, 但是, 由于土地利用/覆盖变化过程复杂且影响广泛, 对于如何量化两者之间的关系 还存在很多不确定性。目前的量化过程主要是利用经验数据来实现的 机理性不强, 使得对土地利用/覆盖变化造 成的陆地生态系统 $\mathrm{CO}_{2}$ 释放量的估测差异很大。除了进一步加强长期定位研究以获得土地利用/覆盖变化与生态 系统碳循环过程的定量关系外, 土地利用/覆盖变化模型与植被动态模型、生态系统过程模型的耦合也是今后模型 发展的主要方向之一。采用合理的管理措施能够大量增加土地利用/覆盖变化过程中的碳储存量, 降低碳释放量, 因此在模型中耦合管理措施来研究土地利用/覆盖变化过程对生态系统碳循环的影响是未来几年的工作重点。

关键词 土地利用/覆盖变化 陆地生态系统 模型 碳循环 碳源/汇

\section{LAND USE/COVER CHANGE EFFECTS ON CARBON CYCLING IN TERRESTRIAL ECOSYSTEMS}

CHEN Guang-Sheng and TIAN Han-Qin *

Ecosystem Science and Regional Analysis Laboratory , School of Forestry and Wildlife Sciences , Auburn University , Auburn , AL36849 , USA

\begin{abstract}
Land use/cover change (LUCC) is one of the most concerned environmental problems by scientists , land managers and policy makers. LUCC can affect energy flow , biogeochemical and hydrological cycling in terrestrial ecosystems through altering land surface and species composition. Ecosystem carbon cycling responds differently to various LUCC types, showing a pattern of $\mathrm{CO}_{2}$ release into the atmosphere when LUCC from a high-biomass forest to low-biomass grassland, cropland or urban area. Previous reports indicated that global terrestrial ecosystem released $2.21 \mathrm{Pg} \mathrm{C}\left(1 \mathrm{Pg} \mathrm{C}=10^{15} \mathrm{~g} \mathrm{C}\right)$ per year induced by LUCC during the 1990s , which explains about $25 \%$ of the global C emission per year in the same period ; and in the last two centuries, the released C from LUCC accounts for $50 \%$ of the $\mathrm{C}$ emission from fossil fuel combustion. The LUCC patterns are totally diversified for regions around the world, which cause obviously different $\mathrm{C}$ fluxes among them. The reports showed that LUCC in the tropics is a C source, while it is a $\mathrm{C}$ sink in the middle and high latitude regions in the northern hemisphere, which possibly explain a large part of the " missing carbon sink" in the terrestrial ecosystems. Currently, modeling is the most popular way to simulate LUCC-induced changes in ecosystem C cycling. The quantitative relationship between LUCC patterns and their related processes and ecosystem carbon cycling remains uncertain. This uncertainty causes great discrepancies in the estimation of terrestrial ecosystem $\mathrm{CO}_{2}$ fluxes from land use/cover changes. In the near future , except for carrying on long-term experiments to determine these quantitative relationships, model development by integrating LUCC with vegetation dynamic model and ecosystem process model will be essential for making an accurate estimation of C fluxes induced by LUCC. Sound land management can greatly increase C storage in the terrestrial ecosystems during LUCC processes. However, the quantification of land management effects is not well-established yet and land management is thus not included in most simulation models of LUCC impacts, which needs more researches in the future.
\end{abstract}


Key words land use/cover change (LUCC), terrestrial ecosystems , carbon cycle model , carbon cycling , carbon sink and source

土地利用/覆盖变化 ( LUCC) 是除了工业化之 外, 人类对自然生态系统的最大影响因素 (Turner et al . , 1997 ; Lambin et al . , 2001) ,对土地利用/覆盖 变化的影响的研究实际上就是对人类与土地关系的 探讨。土地利用/覆盖变化是未来几十年间人类社 会面临的最大挑战之一:陆地生态系统必须提供满 足人类和其它物种需求的足够食物, 并提高数量不 断增长的人类的生活质量, 同时保持土地利用的可 持续性。然而，农田面积扩大、城市用地增加和森林 砍伐等用于满足人类需求的措施正在毁坏土地利用 /覆盖的可持续性。目前, 许多政府和研究机构正在 广泛关注土地利用/覆盖变化产生的后果。跨国研 究项目不断增加, 比如, 美国 NASA 土地利用/覆盖 变化研究项目 (The land use and land cover change program of the national aeronautics and space administration)、美国政府气候变化科学项目中的土地利用/覆 盖子项目 (the land use program element in the interagency U.S. climate change science program)、以及 IGBP 土地利用/覆盖变化核心项目 (the international geosphere-biosphere' s land use and cover change (LUCC) core project)、国际应用系统分析研究所土地利用/覆 盖和农业研究项目 (land use change and agriculture program, international institute of applied systems analysis, IIASA)等。

为什么土地利用/覆盖发生变化 ? 土地利用/覆 盖变化在何时、何地发生? 它是如何发生的? 土地 利用/覆盖发生变化的后果是什么? 这些都是土地 利用/覆盖变化研究中要回答的基本问题。从这些 问题出发, 过去 50 年间, 陆地生态系统对土地利用/ 覆盖变化的响应已开展了大量研究, 并取得了很多 成果 理论分析结合调查数据统计是最为普遍的研 究途径, 而近 20 多年以来, 随着卫星遥感技术的发 展以及实验方法的不断提高和模型开发、应用的逐 渐成熟 利用遥感和模型方法来研究大尺度土地利 用/覆盖变化对生态系统过程的影响成为最有效的 手段。土地利用/覆盖类型是决定陆地生态系统碳 储存的重要因素, 土地覆盖形式由一种类型转变为 另一种类型往往伴随着大量的碳交换 (Bolin \& Sukumar, 2000)。随着地理信息系统、遥感和模型的发 展，对土地利用/覆盖变化本身的研究越来越成熟; 而同时随着对土地利用/覆盖变化生态效应的研究
逐渐增多, 土地利用/覆盖变化对生态系统碳循环的 影响机制也逐渐清晰。但是, 目前在大尺度上利用 遥感和模型手段估算土地利用/覆盖变化对生态系 统碳氮循环的影响还存在很大的不确定性。在全球 碳平衡的计算中, 土地利用/覆盖变化是估测陆地生 态系统碳储存和碳释放中最大的不确定因素 (King et al . , 1995 ; Levy et al . 2004)。对 20 世纪 90 年代 的碳平衡估算发现, 10 年期间全球每年大约有 2.9 Pg C $\left(1 P g=10^{15} \mathrm{~g}\right)$ 的 碳失汇” (Missing carbon sink) (Schimel et al. , 2001)。由于海洋碳汇较小 (约为 $2.0 \mathrm{Pg} \mathrm{C}: \mathrm{a}^{-1}$ ), 不确定性也很小 ( Siegenthaler \& Oeschger, 1978) , 因此, 全球碳汇的增加大部分存在 于不确定性很大的陆地生态系统中 (Tans et al. , 1990)。这些 失汇” 被认为可能来源于植物生长量 的增加 (Schimel , 1995 ; Keeling et al ., 1996 ; Walker et al., 1999 ; Caspersen et al. ,2000)或土壤碳储存 增加 (Fisher et al . , 1994 ; Schlesinger , 1999 ; Pacala et $a l$. , 2001) ,而土地利用/覆盖变化无疑是影响植物 生长和土壤碳储存量的主要原因之一 ( Canadell, 2002)。

本文比较全面地综述了全球和区域水平的土地 利用/覆盖格局以及土地利用/覆盖变化对陆地生态 系统碳储存和碳通量的影响, 评述了土地利用/覆盖 变化引起生态系统碳循环改变的研究方法, 同时指 出该领域研究中的几点问题和今后的发展方向。

\section{1 全球区域土地利用/覆盖变化格局}

土地利用/覆盖变化的驱动力很多, 可以分为人 为因素和自然因素, 其中以人为因素占主导, 主要包 括区域经济、社会和自然历史等。土地利用/覆盖变 化的多驱动因子增加了土地利用/覆盖变化历史以 及土地利用/覆盖变化对生态系统影响的复杂度, 进 而造成估算土地利用/覆盖变化对生态系统碳储存 和碳通量的不确定性。经济体制和政策、社会结构 和制度、文化和文明程度以及自然土地利用历史等 都影响着土地利用/覆盖变化，从而间接影响着生态 系统的碳循环过程。因此, 分析土地利用/覆盖变化 的区域格局是估算土地利用/覆盖变化发展及其对 生态系统碳循环过程影响的前提和基础。目前, 估 测土地利用变化的方法以模型为主, 主要包括统计 模型和过程模型 ( 又称结构模型)两种 (Veldkamp \& 
Lambin , 2001)。随着模型的逐步改进和遥感数据的 进一步完善 土地利用/覆盖历史以及未来土地利用 格局的估测越来越准确。

与潜在植被类型分布区域和面积相比, 全球陆 地大约有 $(32.5 \sim 34.7) \times 10^{6} \mathrm{~km}^{2}$ 的自然植被转变为 非自然植被，约占陆地面积的 $10 \%$ (DeFries et al. , 1999)。依据 Ramankutty 和 Foley(1999)的研究结果, $1700 \sim 1992$ 年, 全球共有 $11.4 \times 10^{6} \mathrm{~km}^{2}$ 的森林转化 为农田, 6.7 $\times 10^{6} \mathrm{~km}^{2}$ 的草地转化为农田。特别是 近 50 年来 城市面积的快速扩张更是加剧了陆地生 态系统从自然植被向城市用地的转化。

受社会和经济条件的制约，世界各地的土地利 用/覆盖变化趋势不尽相同。亚洲森林面积从 1990 年以来变化很小(约每年减少 $0.03 \%)(\mathrm{FAO}, 2005)$, 但是，亚洲不同区域的森林面积变化趋势却差异显 著 表现为东亚、西亚和中亚地区森林面积为净增 加, 而南亚和东南亚森林面积略有下降。1700 年至 20 世纪 70 年代, 中国的森林面积不断减少而农田 面积不断增加 (Houghton \& Hackler, 2003)。近 30 年 来, 受到政府 退耕还林还草”政策的影响, 中国大量 荒漠地、农田都转化为了草地或林地, 中国的六大造 林工程 ( 天然林资源保护工程、退耕还林工程、三 北” 及长江中下游等重点防护林体系建设工程、京津 风沙源治理工程、野生动植物保护及自然保护区建 设工程、重点地区速生丰产用材林基地建设工程)促 使森林覆盖率不断增加。尽管中国最近的农田面积 变化趋势存在争议,一些研究结果以及政府统计数 据显示中国的农田面积自 1990 年以来在不断减少 (Houghton \& Hackler , 2003 ; 中华人民共和国国土资 源部，2000，2001，2002，2003）;而另一些研究者却 认为中国农田面积在不断增加 (FAO, 2005 ; Liu et $a l$. 2005a，2005b)。中国另外一个土地利用/覆盖 变化的趋势就是, 中国近 20 年来的城市用地大部分 是由农田转化而来的 ( Liu et al . 2005b) ,由于农田 和城市的碳释放量相当, 因此可以认为, 中国城市化 和工业化造成的土地利用/覆盖变化对生态系统碳 循环的影响并不显著。而在美国、加拿大、俄罗斯等 国家, 由于目前森林覆盖面积很高, 农田面积相对较 少, 大量城市用地是由森林转化而来的, 因此, 这些 地区的城市化趋势可能造成大量的碳排放。自 1990 年以来, 中美和北美洲的森林面积基本不变 (或略有降低)。自 1860 年以来, 美国南部的农田面 积表现出先增加 (1860 1940 年) 后减少 (1940 2000 年)的趋势, 同时, 森林面积表现出相反的变化
趋势, 草地和灌丛面积持续减少、城市面积持续增加 (Chen et al . ,2006) ,而 2000 2005 年, 由于造林面 积锐减以及砍伐量增加, 整个美国的森林面积出现 缓慢减少趋势。欧洲森林面积在最近 15 年间以每 年 $0.08 \%\left(80.5 \times 10^{4} \mathrm{hm}^{2}\right)$ 的速度增加。而在非洲和 南美地区 林业是许多国家的支柱产业之一，同时， 也为了满足食物需求, 森林砍伐的速率惊人。仅从 1990 2005 年, 非洲森林面积就以大约每年 400 万 $\mathrm{hm}^{2}$ 的速度减少。南美地区的森林面积在最近 15 年中以每年 $(80 \sim 480) \times 10^{4} \mathrm{hm}^{2}$ 的速度降低 (FAO， 2005)。一个典型的例子是亚马逊地区, 该地区大面 积的原始林被砍伐转变为牧场或农田 (Allen \& Barnes , 1985 ; Skole \& Tucker , 1993)。

据 IPCC 估算，热带地区森林的总碳储量为 428 $\mathrm{Pg} \mathrm{C}$, 仅次于北方森林, 是陆地生态系统第二大碳储 存区域 ( IPCC, 2000) ,但是, 遥感数据发现, 从 1990 到 1997 年间, 这一区域每年有 $(5.4 \pm 1.4) \times 10^{6}$ $\mathrm{hm}^{2}$ 的森林被砍伐, 同时, 每年有大约 $(2.3 \pm 0.7)$ $\times 10^{6} \mathrm{hm}^{2}$ 的森林退化 (Achard et al. ,2002) ,引起大 量的碳排放。在所有的热带森林中，亚洲地区森林 砍伐率最高，其次为拉丁美洲和非洲，再次为美洲。 但是, 由于美洲热带森林面积(主要是亚马逊热带森 林) 最大, 据 FAO 统计, 近 20 年来 (1980 2000 年) 美洲热带地区森林砍伐面积最大为 $1.20 \times 10^{7} \mathrm{hm}^{2}$, 其次为亚洲 (包括大洋洲, $0.97 \times 10^{7} \mathrm{hm}^{2}$ ) 和非洲 ( 0 . $96 \times 10^{7} \mathrm{hm}^{2}$ ) ( Houghton, 2003)。亚洲地区以中国 的森林面积变化最大, 1980 2000 年间造林面积达 $0.53 \times 10^{7} \mathrm{hm}^{2}$, 从一定程度上抵消了森林砍伐造成 的大量碳释放，而美洲和非洲造林面积分别为 0.59 $\times 10^{6} \mathrm{hm}^{2}$ 和 $0.38 \times 10^{6} \mathrm{hm}^{2}$ 。热带森林面积最大的 南美亚马逊地区 (Amazonian) 近 50 年来滥砍滥伐非 常严重, 尽管从低分辨率的遥感数据和当地统计数 据来看，该地区的森林砍伐率低于其它热带森林区， 更详细的资料却表明,由于频繁的火灾和大量小面 积的砍伐 (统计资料没有记录) , 该地区的实际森林 损失率被低估很多，每年没有记载的森林砍伐达到 了10000 15000 km², 而由于厄尔尼诺现象引起的 干旱, 使得该地区受火干扰影响的森林面积更大 (Nepstad et al . , 1999 ; Siegert et al ., 2001 ; Fearnside \& Barbosa , 2004)。

地球不同纬度的土地利用/覆盖变化格局也不 同, 有研究表明, 在低纬度地区热带森林面积不断减 少、土地利用/覆盖变化表现为碳源的同时, 北半球 中、高纬度地区森林面积以及森林生长量却不断增 
加, 许多研究都认为北半球中、高纬度地区土地利用 /覆盖变化是陆地生态系统的重要碳汇, 可能是陆地 生态系统 碳失汇”的主要原因之一 ( Fan et al. , 1999 ; Houghton, 2003)。由于原始林转化为次生林 或森林生态系统退化以及森林或农田转化为草地和 农田等, 发生在低纬度森林区域的土地利用/覆盖变 化已经造成每年大约 $(1.65 \pm 0.4) \mathrm{Pg}$ C 释放到大气 中(Dixon et al . , 1994)。

\section{2 土地利用/覆盖变化对主要生态系统碳过 程的影响}

土地利用/覆盖变化可以通过改变生态系统的 结构 (物种组成、生物量) 和功能 (生物多样性、能量 平衡、碳、氮、水循环等) 来影响生态系统碳循环过 程。土地利用/覆盖类型的改变对于生态系统的结 构能够产生很大影响。生态系统的物种组成和生物 多样性将会产生很大变化 (Reidsma et al. , 2006), 比 如, 森林变为草地后, 植被组成将会明显不同, 而当 森林/草地变为农田后, 生物多样性下降。在极端条 件下, 甚至会造成外来物种的入侵 (Parsons，1972;

Yetman \& Burquez, 1994; D' Antonio \& Vitousek, 1992 ; Vitousek et al. , 1997 ; Dukes \& Mooney, 1999) 和土地的严重退化, 比如, 许多研究都发现, 由于灌 木和乔木的扩散引起 肥岛”现象“( Islands of fertility" 或者 Fertile island”) 的产生, 从而造成草地逐渐 荒漠化的现象 (Schlesinger et al., 1990 ; 陈广生等, 2003)。许多物种的灭绝除了受到气候和地质因素 以及人为采摘/猎杀影响外,一个重要的原因就是土 地利用/覆盖变化 (Reidsma et al. , 2006 ; Dukes \& Mooney, 1999)。土地利用/覆盖类型的转变也会显 著影响生态系统各部分(比如地上部分、土壤、根系、 调落物等) 的碳分配状况, 比如森林转化为农田, 地 上部分的碳将会大量减少, 而地下部分碳含量(根系 和土壤)也会逐渐降低，从而造成碳在生态系统中的 分配发生变化。

土地利用/覆盖变化也会影响陆地生态系统的 功能, 改变生态系统的小气候状况 (Scott et al. , 1999) 以及物理化学性质, 从而影响调落物的质量 (碳氮比、单宁和纤维素含量等)和分解速率、土壤生 物 (动物和微生物) 组成、土壤物理结构 (砂砾、粘粒、 粉粒组成以及土壤粘聚体结构) ( Heal et al., 1997)、土壤碳、氮、水含量、土壤有机质质量 (易分解 和不易分解的有机质比例) ( Heal et al ., 1997 ; Tate et al. ,2000 ; Islam \& Weil ,2000)等。这些因素进而
都会影响生态系统碳循环过程, 进一步影响到生态 系统的碳储存和释放。因此, 土地利用/覆盖的改变 将会对生态系统的碳循环产生巨大影响, 而不同类 型的土地利用/覆盖变化对于生态系统碳循环的影 响是截然不同的。

\section{1 森林、草地与农田的相互转化}

森林生态系统是最大的陆地碳库，因此，即使森 林面积发生很小的变化, 都可能引起全球陆地生态 系统碳循环的极大变化。由于造林 (Afforestation)、 再造林 (Reforestation) 和森林砍伐 (Deforestation) 的统 计数据目前还有很多不确定性, 对森林转化为草地 和农田所造成的碳收支估测很不一致。据 Dixon 等 (1994)估算, 20 世纪 90 年代, 全球森林面积为 $4.1 \times$ $\mathrm{G} \mathrm{hm}$ 、地上部分碳䛎量为 $360 \sim 480 \mathrm{Pg}$ 、地下部分为 $790 \sim 930 \mathrm{Pg}$, 分别约占陆地生态系统地上碳咜量、地 下碳贮量 (土壤、枯落物和根系) 和土壤碳贮量的 $82 \% \sim 86 \% 、 40 \%$ 和 70\%～73\%。关于森林生态系 统碳储存的区域分布格局, 低纬度森林占 $37 \%$, 中 纬度森林占 $14 \%$, 高纬度森林占 $49 \%$ 。低纬度地区 由于森林的砍伐, 每年释放碳达 $(1.6 \pm 0.4) \mathrm{PgC}_{0}$ 中高纬度地区由于森林的恢复和再生长每年大约固 碳 $(0.7 \pm 0.2) \mathrm{PgC}$, 因此, 中高纬度的森林被认为 是陆地生态系统 碳失汇” 的主要来源 (Kauppi et al., 1992 ; Sedjo, 1992 ; Dixon et al., 1994)。整个 陆地由于森林生态系统的变化每年向大气释放碳 $(0.9 \pm 0.4) \mathrm{PgC}_{0}$

当森林转化为草地时, 大部分的地上生物量碳 将以 $\mathrm{CO}_{2}$ 的形式释放到大气中，尽管 $\mathrm{CO}_{2}$ 释放速率 受人类利用方式的影响。同时，树木根系的分解也 会释放大量 $\mathrm{CO}_{2}$ 。由于森林的地上和地下生物量在 大多数情况下都高于草地的相应部分, 因此, 森林转 化为草地的过程是大气 $\mathrm{CO}_{2}$ 的净释放源。但是, 部 分研究表明, 这种土地利用/覆盖转化方式也有可能 增加或减少土壤的有机碳库, 甚至不产生任何影响， 也就是说, 森林转化为草地后, 土壤可能成为碳汇或 碳源 (Houghton, 1995 ; Post \& Kwon , 2000 ;Franzluebbers et al. ,2000)。土壤的碳源/汇关系主要取决于 草地类型、草地所处的气候区域、干扰状况以及管理 措施等。Tate 等 (2000) 在对山地山毛榉 (Nothofagus sloandri var. cliffortiodes) 转化为一种丛生草地 (Chionochloa pallens) 的研究中发现, 转化后草地的 土壤碳储量比相应的山毛榉林地高出 $13 \%$ 。这种 现象的产生可能是由于这种草本植物的调落物中含 有更多难以分解的碳组分 (Tate et al. ,2000)。Fish- 
er 等(1994)研究也认为, 尽管南美洲热带地区的森 林砍伐造成了大量碳释放，但是，经森林砍伐迹地演 替而来的草地具有更高的土壤碳储量，从一定程度 上减弱了森林砍伐造成的碳释放，他们估计整个南 美洲草地土壤每年能够固定大约 $100 \sim 507 \mathrm{Mt}$ 的 碳, 这可以部分解释陆地生态系统 碳失汇”。Fisher 等的估算受到了其它研究者的质疑。Davidson 等 (1995) 认为 Fisher 等可能高估了草地土壤的固碳潜 力,Fearnside 和 Barbosa(1998)也发现南美洲亚马逊 地区(Amazonia) 热带森林转化为草地后, 土壤表现 为净碳源，在森林转化为草地后的 10 年中共有 12.0 $\mathrm{Mg} \mathrm{G} \mathrm{hm}{ }^{-2}$ 的土壤碳释放到大气中。不同的管理措 施可能是造成这种差异的根本原因。在巴西亚马逊 的马瑙斯 (Manaus) 地区，Cerri 等 (1991) 和 Teixeira (1987) 研究发现, 良好的草地管理措施增加了土壤 碳储存量 (森林土壤碳储存为 $90 \mathrm{Mg} \mathrm{G} \mathrm{hm}{ }^{-2}$, 草地 为 $96 \mathrm{Mg} \mathrm{G} \mathrm{hm}{ }^{-2}$ ), 可能原因是良好的草地管理措 施使草的根系能够分配到更深的土壤, 由于深层土 壤的根系分解速率较慢, 这些根系就保留在土壤中 成为土壤有机质的一部分, 从而增加土壤的碳含量 (Nepstad et al. , 1991)。相反 未管理或管理措施不 合理将会使森林转化为草地后土壤碳储存量大幅减 少。Serrão 和 Falesi (1977) 及 Eden 等(1991) 发现, 森 林转化为草地后的 11 年内, 由于不合理的管理措 施，巴西亚马逊区域的 Mato Grosso 省和 Roraima 省 的草地碳储量比原来的森林土壤分别减少了近 50\%和 15\%。而 Detwiler(1986) 也发现森林转化为 草地后, 如果不进行管理, 全球热带地区 $0 \sim 40 \mathrm{~cm}$ 深度内的土壤碳储存将减少 $20 \%$ 。Guo 和 Gifford (2002) 通过总结分析 176 个研究样点数据后发现， 森林转化为草地后, 土壤的碳源/汇关系可能取决于 区域降水量和土壤取样深度 ,2000 3000 mm 降雨 量的区域, 森林转化为草地后土壤是一个碳汇(土壤 碳储量增加 $24 \%$ ），其它情况下土壤碳储量可能不 变或减少; 而如果取样深度小于 $100 \mathrm{~cm}$, 森林转化为 草地后土壤表现为碳汇(增加 7\% 13\%), 但是, 如 果取样深度超过 $100 \mathrm{~cm}$,则碳汇和碳源的可能性都 有。

在森林或草地生态系统中，植物体咜存的碳通 过分解等方式进入到土壤中, 因而森林和草地土壤 在植被演替过程中土壤碳储量有可能不断增加直到 演替的顶级阶段 (Waring \& Running，1998)。与森林 转化为草地不同的是, 当森林或草地转化为农田后， 大部分的农田地上生物量都被收获, 而只有很少农
作物残茬遗留在土壤中 (尽管农田的每年生产力都 很高)。这些被收获的生物量最终都以 $\mathrm{CO}_{2}$ 的形式 释放到大气中。同时,由于耕种措施的采用，农田土 壤有机质的分解速率加快, 因此, 无论是草地还是森 林转化为农田后, 土壤的碳储量都会减少 (Houghton \& Goodale , 2002 ; Guo \& Gifford , 2002) ,而土壤碳储 量减少速率受周转时间、农田管理措施以及农作物 种类等因素影响。因此, 森林和草地向农田的转化 都会造成大量土壤有机碳释放到大气中。Mann (1986) 通过对 625 个研究样点的数据总结分析发 现,由森林或草地转化为农田可以造成 $0 \sim 100 \mathrm{~cm}$ 土壤内 $20 \%$ 的有机碳释放到大气中 ;Johnson (1992) 通过总结 8 篇文章的研究结果也发现, 约 $20 \%$ $(15 \% \sim 25 \%)$ 的土壤有机碳释放到大气中;Davidson 和 Ackerman(1993) 及 Murty 等 (2002) 经过分析总结 的实验数据, 发现森林或草地向农田的转化能导致 $30 \%$ 左右的土壤有机碳释放到大气中;而 $\mathrm{Guo}$ 和 Gifford(2002)通过对数据分析发现有 $42 \%$ 的土壤有 机碳释放到大气中。Houghton 和 Goodale (2004) 通过 进一步总结分析更全面的实验数据, 认为从草地或 森林转化为农田将会有约 $27 \%$ 的土壤有机碳被释 放到大气中。考虑到土壤是陆地生态系统的第一大 碳库, 而且农田面积还正在不断增加, 尤其是发展中 国家, 森林或草地向农田的转化是除工业化外造成 大气 $\mathrm{CO}_{2}$ 含量急剧增加的最主要原因。

2.2 木本植物入侵草地以及外来物种入侵引起的 土地覆盖变化

在许多贫痊的干旱、半干旱地区,由于抑制火 烧、过度放牧、人为干扰强烈、气候变化异常等原因 造成大量的木本植物入侵草地并在草地中大幅扩 散, 这种木本植物的扩散是一种比较缓慢、不易觉察 的土地利用/覆盖变化过程。这种土地利用/覆盖的 变化有别于正常的草地向木本植物的土地覆盖变 化, 它可能引起地上生物量和地下部分碳含量的改 变, 生态系统退化等后果。从 20 世纪 60 年代开始， 陆续出现许多关于干旱、半干旱地区的草原生态系 统被灌木或乔木生态系统所取代的报道 (Crawford \& Gosz , 1982 ; Grover \& Musick , 1990 ; Archer et al. , 1995 , 2001 ; Schlesinger et al. , 1990 ; Van Auken , 2000）这些研究报道均显示,在干旱或人为干扰强 烈的草地生态系统中灌丛土壤资源的局部聚集现象 (被称为 肥岛”现象)，资源不断聚集导致灌丛分布 面积的逐步扩大，灌丛面积的扩大反过来加速了灌 丛土壤养分的聚集, 这种灌丛与土壤之间的正反馈 
效应加速了荒漠化的形成过程 (Schlesinger et al. , 1990) ,并且直接导致了灌丛-荒漠(Shrub-desert)或灌 丛干草原(Shrub steppe, 只有灌丛存在, 灌丛之间是 裸露的空地) (Crawford \& Gosz, 1982) 的形成。这种 土地覆被类型转化的生态后果通常是严重地破环了 养分循环和水分收支等生态系统功能, 使其只适应 这些入侵/扩散的木本植物的生长, 土壤养分和碳含 量的空间异质性增加, 整个土壤生态系统碳含量发 生变化。木本植物入侵/扩散进入草地或沙漠被认 为能够增加这个系统的植被碳储量。Houghton (2003) 估算木本植物的入侵使全球在 20 世纪 90 年 代每年大约固碳 $0.04 \mathrm{PgC}$, 他的估算只是通过植被 生物量换算而来,并没有考虑土壤碳含量的变化。 有研究发现, 木本植物的扩散也能够增加土壤碳含 量(Hibbard et al. ,2001)或使土壤碳含量维持不变 (Smith \& Johnson，2003)。但是,利用 2700 多个土 壤剖面资料、Jackson 等(2002)发现了相反的现象, 他 们的研究表明, 在木本植物入侵/扩散到草地的过程 中，尽管一些湿润地区的植物生物量和土壤碳含量 增加了, 但是较干旱区域的土壤碳含量降低得更多， 这种降低足以抵消湿润区域的碳增加量。因此, 两 者累加后, 整个入侵/扩散过程使该生态系统表现为 碳源。Jackson 等认为, 目前的许多研究可能高估了 土地利用/覆盖变化对生态系统碳库的贡献。这种 由灌木/乔木扩散/入侵草地引起的生态系统碳交换 的机理和结果完全不同于由人工栽种、自然萌发、生 态系统恢复等引起的土地利用/覆盖变化 (草地变灌 木地或森林)。由于这种木本植物的入侵/扩散现象 在许多干旱、半干旱地区都出现了，入侵/扩散面积 正在不断增加 (Scott et al ., 2006), 因此, 今后的模 型模拟研究中有必要区分两种类型, 以免对土地利 用/覆盖变化引起的陆地碳汇造成误估。

外来物种入侵造成的生态系统碳交换的变化类 似于木本植物向草地的扩散。目前, 尽管许多研究 表明,由外来物种的入侵引起的土地利用/覆盖类型 的变化会使整个生态系统的结构和功能发生很大变 化, 甚至使这个系统产生退化, 但是, 外来物种入侵 如何影响整个生态系统的碳交换仍然不甚明了, 有 待于更多的研究来进行揭示。

\section{3 旱地与湿地的相互转化}

目前, 全球湿地生态系统面积约为 $530 \sim 570$ $\mathrm{Mhm}^{2}$ 约占整个陆地面积的 4\% 6\% (Matthews \& Fung , 1987 ; Aselmann \& Crutzen , 1989) 总碳储量为 $350 \sim 535 \mathrm{Pg} \mathrm{C}$, 大约相当于世界土壤有机碳含量的
$20 \% \sim 25 \%$ (Gorham, 1995)。由于人口的持续增加 和工业化进程的不断加快, 世界范围内的许多湿地 生态系统(不包括水稻等人工湿地, 特指自然湿地生 态系统) 都转化为旱生植被生态系统、城市用地或农 田。尤其是在中国, 调查发现，从 20 世纪 50 年代至 90 年代中期,中国湿地面积锐减了 $50 \%$, 其中，从 1990 到 2000 年中国湿地面积减少了 $14.83 \%$ 。目 前, 中国自然湿地面积为 2594 万 $\mathrm{hm}^{2}$ (Zhang et al. , 2004)。而且尽管湿地面积减少速率下降, 但是, 这 种减少趋势还在继续。湿地生态系统是陆地生态系 统的重要碳库(IPCC, 2001 ; Patterson，1999) 约占全 球陆地生态系统碳库的 $10 \%$ 。尽管自然湿地是 $\mathrm{CH}_{4}$ 释放的重要源(约占全球 $\mathrm{CH}_{4}$ 释放量的 $20 \%$,Khalil \& Rasmussen, 1983), 但是, GACGC(1998) 认为 $\mathrm{CH}_{4}-\mathrm{C}$

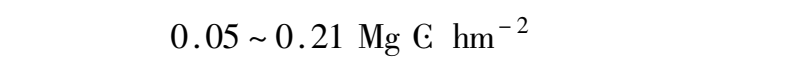
对 $\mathrm{CO}_{2}-\mathrm{C}$ 的吸收量, 因此, 整个自然湿地生态系统还 是重要的碳汇。GACGC(1998) 估计全球湿地平均每 公顷每年固定 $0.1 \sim 0.35 \mathrm{Mg} \mathrm{C}$, Gorham(1991) 估计 全球沼泽每年总固定 0.1 Pg C。而Wojick(1999)却 认为全球湿地每年固定 $0.1 \sim 0.7 \mathrm{Pg} \mathrm{C}$, 与湿地释放 的 $\mathrm{CH}_{4}-\mathrm{C}$ 相互抵消之后, 整个自然湿地生态系统表 现为一个弱碳源。由于 $\mathrm{CO}_{2}$ 的吸收和 $\mathrm{CH}_{4}$ 的释放 过程都很复杂而且相互影响, 目前, 湿地生态系统的 碳源/汇关系仍然存在较大争议。

尽管如此，如果湿地生态系统遭到破坏或转化 为其它土地利用/覆盖类型 将会释放大量的碳。在 湿地逐渐旱化过程中，尽管植被生物量碳可能增加， 比如, 草地湿地转化为林地, 但是除了一些沙质和裸 露湿地外, 大多数情况下, 都会造成更多的土壤碳释 放到大气中 (Mitra et al . 2005)。湿地旱化过程中， 由于异氧环境的逐渐消失, 湿地表层土壤中的大量 有机物分解就会加速, 导致大量土壤有机碳释放到 大气中。Kasimir-Klemedtsson 等 (1997) 研究发现, 沼 泽转化为农田后, 能够导致 $5 \sim 23$ 倍的 $\mathrm{CO}_{2}$ - $\mathrm{C}$ 释放 到大气中, $\mathrm{CO}_{2}-\mathrm{C}$ 的净释放增加量远大于 $\mathrm{CH}_{4}-\mathrm{C}$ 排 放减少量。Maltby 和 Immirzi ( 1993 ) 认为, 湿地旱化 可以导致整个生态系统释放 2.5 10 $\mathrm{Mg} \mathrm{G} \mathrm{hm}{ }^{-2}$. $\mathrm{a}^{-1}$, 而热带湿地旱化则可能造成每公顷释放多达 $40 \mathrm{Mg} \mathrm{G} \mathrm{hm} \mathrm{hm}^{-2} \mathrm{a}^{-1}$ 。GACGC 则认为湿地旱化和转 化为农田会造成生态系统释放碳量达 $0.23 \sim 0.26$ 和 $1 \sim 10 \mathrm{Mg} \mathrm{C} \mathrm{hm} \mathrm{ha}^{-2} \mathrm{a}^{-1}$,与 Maltby 和 $\operatorname{Immirzi}(1993)$ 的估算值 $\left(0.05 \sim 0.11 \mathrm{Mg} \mathrm{G} \mathrm{a}^{-1}\right)$ 相当。

通常情况下, 旱地向湿地的转化与湿地向旱地 的转化过程相反。目前，对土地利用/覆盖的所有研 
究中, 很少关注到旱地向湿地转化所引起的生态系 统碳储存或释放的变化 (Mitra et al ，, 2005)。由于 湿地生态系统类型多样、生态过程非常复杂以及系 统异质性很大 模拟湿地生态系统碳循环的过程也 非常困难, 目前的估算结果仍然存在很大的不确定 性。因此在以后的研究中, 模型发展和站点试验研 究方面都有待于加强。

\section{4 城市与非城市用地的转化}

城市扩张 (这里所指的城市不包括城市森林或 草地) 是最为重要的土地利用/覆盖变化类型之一。 目前 城市面积的扩展速度已经超过了人口的增加 速度 (Johnson，2001)。由于城市化会带来大量的工 业碳释放，因此城市化现象备受关注，而城市化带来 的非工业化碳排放的变化却很少引起人们的注意。 城市用地的来源有很多种, 有水域、森林、草地、裸地 或农田等, 由此带来的非工业碳排放的变化就存在 很大差异。如果森林或草地转化为城市用地,由于 植物地上生物量会以 $\mathrm{CO}_{2}$ 的形式释放到大气中, 这 种转化表现为碳源; 而如果农田转化为城市用地, 由 于农田被认为是碳源，而城市非工业化碳释放被认 为是零, 那么这种转化过程就表现为碳汇。目前, 中 国、印度等大多数发展中国家的城市用地都是由农 田面积转化而来，而美国、加拿大、西欧等国家的城 市面积大部分从森林转化而来, 相比之下, 中国、印 度等国的城市扩张可能会减少该国的碳释放，而美 国等发达国家的城市化则可能是碳源。尽管这个结 论目前并没有明确的证据, 但是, 这个结论的产生是 合理的。另一个研究城市化对碳循环影响被忽略的 方面是, 城市用地(水泥、柏油或其它不透水层)下土 壤碳的去向问题。被封存在城市用地下的土壤碳能 否释放出来呢? 如果会的话, 那么目前大多数模型 都把城市看成是一个零 (或很低) 碳释放量的区域, 将低估土地利用/覆盖变化引起的生态系统碳释放。 城市用地下的土壤碳是否会释放到大气中来还有待 于今后的试验验证。

\section{3 模拟土地利用/覆盖变化对生态系统碳循} 环的影响

\section{1 模型研究结果与方法进展}

尽管遥感方法在估算土地利用/覆盖变化引起 的陆地生态系统碳循环方面取得了很大的进展, 但 是, 由于遥感方法必须依赖于遥感获得的土地利用/ 覆盖参数, 并且对于遥感工具出现前土地利用/覆盖 变化和将来土地利用/覆盖变化对生态系统碳循环
的影响无能为力。另外, 尽管高精度遥感能够获得 植被生态系统的结构、年龄、植物组成和土壤物理化 学特性等信息。但是, 由于工作量很大，在大尺度范 围内无法利用遥感数据及相应遥感模型来估算土地 利用/覆盖改变对生态系统碳循环的影响。因此, 目 前对大尺度土地利用/覆盖变化影响的研究主要借 助于模型。由于对土地利用/覆盖变化带来的生态 系统过程影响的定量化比较困难, 目前模型定量土 地利用/覆盖变化与其影响过程的关系时大都采用 经验数据, 比如 ,Houghton 等 $(1983,1999,2000)$ 、 Houghton $(1995 ， 2003)$ 及 Houghton 和 Hackler (2003) 利用联合国粮农组织 (FAO) 土地利用/覆盖类型统 计数据来统计全球陆地生态系统碳交换时, 就是根 据不同植被类型和不同地区来分别设定固定的参 数，比如，农田向森林恢复的时间以及森林砍伐后的 林木产品的不同分解速率碳库 (分别为 $1 、 10 、 100$ 和 1000 年碳库) 的划分。这种定量化方法称为簿记法 (Bookkeeping)，许多模型中模拟土地利用/覆盖变化 结果的公式都是基于这种方法来设定的, 但由于缺 乏机理过程, 这种方法很难反映真实的土地利用变 化过程对生态系统碳循环的动态影响。而生态系统 过程模型与簿记法的结合, 可以把土地利用变化信 息与其相关过程结合在一起, 在很大程度上提高了 对土地利用变化引起的碳循环动态变化的估算精 度。陆地生态系统模型 (Terrestrial ecosystem model, TEM)中的土地利用/覆盖变化的影响就是基于不同 植被功能群的特定参数来实现的 (McGuire et al. , 2001 ; Tian et al ., 1998b , 2000，2003)。DeFries 等 (1999) 利用遥感数据获得的植被分布信息结合 CASA 模型预测了土地覆盖变化造成的生态系统碳 循环的变化。LPJ 模型 (Lund-Potsdam-Jena dynamic global vegetation model, Sitch et al. , 2003)也把植被 动态模型与簿记法进行了耦合。

McGuire 等 (2001) 分别利用 4 个模型 (TEM， HRBM ,LPJ 和 IBIS)结合 Houghton 等( 1983) 提出的簿 记法, 估算了两种土地利用/覆盖变化情况下生态系 统碳交换的动态变化。这两种情况分别为: : ) 自然 植被(草地、森林)转化为农业用地 , 2)农田生态系统 恢复为自然生态系统。结果表明，从 1920 到 1992 年, 土地利用/覆盖变化造成的陆地生态系统碳释放 量高达 $72.25 \mathrm{Pg} \mathrm{C}$ (4 个模型平均值)。Houghton 等 (1999)认为这段时间内土地利用/覆盖变化引起的 全球陆地生态系统碳释放总量为 $89.31 \mathrm{Pg} \mathrm{C}^{\circ}$ 。尽管 Houghton 估算的生态系统碳释放量与 LPJ 模型估测 
结果的年际变化趋势不一致，但是，两者对土地利用 /覆盖变化造成的陆地生态系统碳释放总量的估算 值相当。Levy 等 (2004) 采用类似 McGuire 等 (2001) 的方法, 把 HYBRID 植被动态模型与簿记法结合来 估算土地利用/覆盖变化引起的全球陆地生态系统 碳交换的变化。他们研究发现,1700 1990 年间土 地利用/覆盖变化造成的碳释放总量为 $222 \mathrm{Pg} \mathrm{C}$, 而 DeFries 等 (1999) 的估算量为 $191 \mathrm{Pg} \mathrm{C}$, 考虑误差因 素可以认为两结果相当; 1850 1990 年间碳释放总 量为 $173 \mathrm{Pg} \mathrm{C}$, 比 Houghton 等(1999)的估算结果 (124 $\mathrm{Pg}$ C) 高了近 $50 \mathrm{Pg} \mathrm{C} ; 1920 \sim 1990$ 年间的碳释放总量 为 $100 \mathrm{Pg} \mathrm{C}$, 比 McGuire 等(2001)的估算结果 (72.25 $\mathrm{Pg}$ C) 高出很多。利用 TEM 模型, Tian 等(2003)发现 1860 至 1990 年间, 全球土地利用/覆盖变化引起的 碳释放总量为 $116.3 \mathrm{Pg} \mathrm{C}$, 这一预测结果与 Houghton 等 (1999)的预测结果相当。对于全球热带地区森林 砍伐造成的碳释放的估算, 不同估算方法得到的结 果不同。模型、遥感与统计结果都有不同程度的差 异 20 世纪 80 年代整个全球热带地区由于森林砍 伐造成的每年碳释放量大概为 $0.64 \sim 2.4 \mathrm{Gt} \mathrm{C}$ 。遥 感模型估算的碳释放量最低, 而统计方法获得结果 最高 模型模拟的结果处于两者之间。这些模型模 拟的结果之间差异的一个来源可能是区域土地利用 /覆盖输入数据的不一致, 另外也有可能是各个模型 本身的过程机制差异引起的。
由于区域土地利用变化趋势不一致,全球各地 区土地利用/覆盖变化造成的生态系统碳释放量差 异也很大。借助 TEM 模型,Tian 等(2003)发现,1860 到 1990 年间亚洲热带地区土地利用变化造成的碳 释放量达 $29.7 \mathrm{Pg} \mathrm{C}$ 约占全球由土地利用变化造成 碳释放的 $25.5 \%$ 。Houghton(2003)的估算则认为(图 1) 热带地区(包括亚洲、非洲和美洲的热带地区)土 地利用/覆盖变化造成的生态系统碳释放量正在逐 年增加 ;中国、前苏联、太平洋发达国家在 20 世纪 60 年代之前碳释放量表现出逐年增加的趋势, 而这之 后则不断下降, 尤其是中国自 20 世纪 80 年代以来 土地利用/覆盖变化造成的碳释放量急剧减少, 这可 能是由于 80 年代开始中国大量人工林的栽种以及 其它土地利用/覆盖类型转化为农田减少所致 (FAO , 2005; Liu et al ，2005a , 2005b) ;加拿大和欧 洲 (不包括前苏联)由于土地利用/覆盖变化造成的 碳释放量很少，从 20 世纪 80 年代开始，欧洲的土地 利用/覆盖变化有转化为碳汇的趋势; 美国自 1920 年 前后开始土地利用/覆盖变化由碳源转化为碳汇, 这 可能是由于 1850 到 2000 年期间美国的农田面积减少 了近 $50 \%$,而且大多数农田都转化为森林 (Chen et al.,2006 ; Houghton \& Hackler, 2000)。尽管对整个 美国陆地生态系统的碳源/汇关系仍然存在争议，但 是 , 土地利用/覆盖变化造成的美国陆地生态系统碳 交换的趋势却很一致 (从碳源转变成碳汇)。

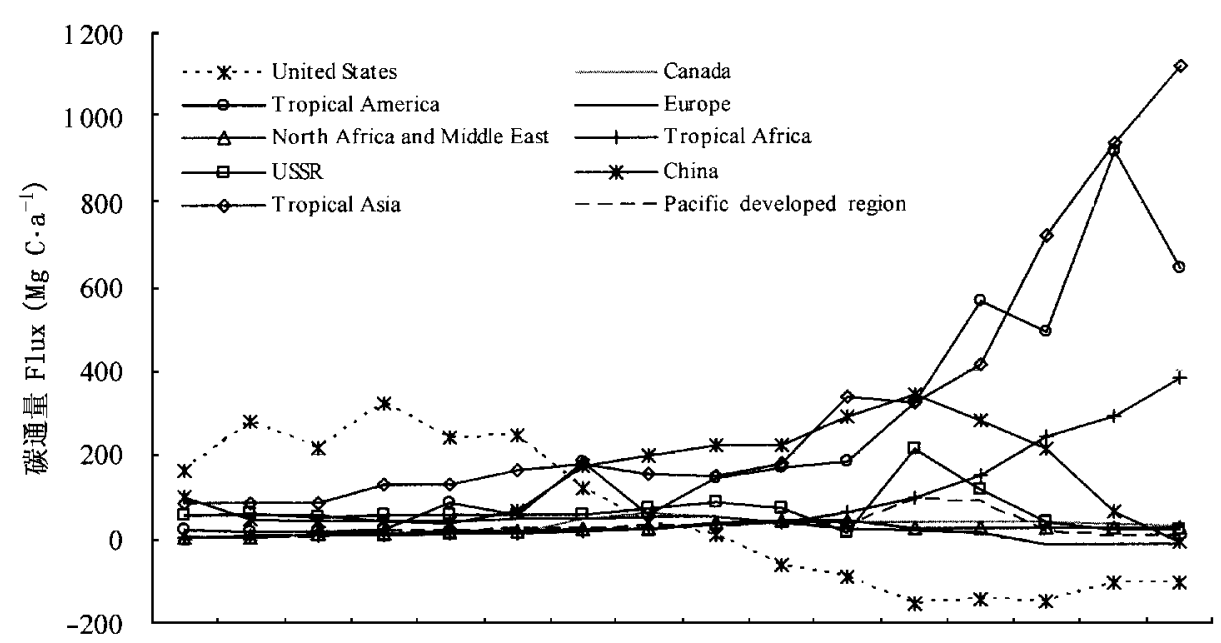

1850186018701880189019001910192019301940195019601970198019902000

年 Year 


\section{2 模型模拟的不确定性因素}

目前，对土地利用/覆盖变化造成生态系统碳循 环变化的研究主要以模型模拟为主。土地利用/覆 盖变化能够影响生态系统的水和养分循环以及能量 流动,并且由于土地利用/覆盖变化过程本身比较复 杂, 目前的模型对土地利用/覆盖变化造成生态系统 碳循环变化过程的模拟还有很多不确定性, 这些不 确定性造成了模型模拟结果的差异性 (Houghton， 2003 ; Levy et al . , 2004)。土地利用/覆盖变化及其 引起的生态系统碳循环过程变化的定量模拟研究起 步比较晚, 开始于 20 世纪 70 年代, 目前处于发展时 期 模型的发展和应用仍然存在很多问题。土地利 用/覆盖变化对碳循环过程影响模拟研究的不确定 性主要存在于 4 个方面:其一,模型对土地利用/覆 盖变化前后的植物生物量变化的估测还不够准确 (森林年龄以及植被演替的影响) 其二, 森林砍伐面 积的估测不准确; 其三, 土地利用/覆盖变化前后土 壤碳库变化的不确定性; 其四, 土地利用变化造成的 水分循环变化对碳循环的影响未加考虑。这些不确 定因素使土地利用/覆盖变化成为目前估算陆地生 态系统碳储存和释放量的最大不确定性因素, 也可 能是 碳失汇”的主要来源。

以往对土地利用/覆盖变化影响陆地生态系统 碳循环的研究主要强调生态系统的静态特征, 很少 考虑森林/草地/灌木生态系统的年龄与植被生长的 动态变化, 因此, 对于土地利用变化后的生态系统生 物量变化估测很不准确。造林、森林的更新以及森 林砍伐等均可以影响林分的年龄结构和生长动态。 目前，许多国家森林面积的维持或增加都是靠造林 面积增加或次生林的更新来实现, 比如, 中国的森林 覆盖度从 1950 年的 5.2\% (Zhang et al .,2000) 增加 到目前的 $16.55 \%$, 就是因为人工林面积的不断增 加，尽管原始林(包括原始次生林)面积在这期间不 断减少;而尽管最近几年造林面积呈现减少的趋势， 美国南部的人工林面积近 50 年来不断扩大, 美国南 部 13 个州的人工林面积超过了当地原始林面积的 $25 \%$ 。人工林的出现以及自然或人为干扰引起的森 林更新, 使得林分年龄结构、林分密度以及植物演替 状态对陆地生态系统生物量影响的估算更加不准 确。因此，森林年龄结构的不确定性对于森林转变 为其它土地利用/覆盖类型过程中碳收支的估算影 响巨大。许多没有包含植被动态和干扰模块的模型 都把森林看成是统一年龄结构甚至作为成熟林处 理, 这有可能夸大森林植被中的固碳量，从而可能高
估土地利用/覆盖变化引起的碳释放量。据 Fang 等 (2001)估算,从 1949 到 1980 年, 中国由于森林生物 量的变化造成的碳排放达 $0.68 \mathrm{PgC}_{\text {。 }}$ 考虑到这期间 中国的森林面积不断扩大, 那么这种由于森林生物 量的碳储存变化造成的碳释放就只能解释为森林年 龄或密度的整体降低。

统计方法、生态系统过程模型和遥感模型对土 地利用/覆盖变化影响的研究都需要精确的土地利 用/覆盖面积和分布数据。目前, 无论遥感图像还是 统计资料对于森林砍伐的面积和农田面积的变化还 存在很多不确定性。森林砍伐的不确定性主要集中 在热带区域,IPCC (2000) 指出对热带森林砍伐面积 的估测误差可能达到 $\pm 50 \%$ ，由此引起的对 20 世纪 90 年代土地利用变化造成的碳释放的估测范围大 约为 $0.8 \sim 2.4 \mathrm{Gt} \mathrm{G} \mathrm{a}^{-1}$ 。研究者对于不同区域热 带森林砍伐面积的估测存在很大差异。目前, 对亚 马逊热带雨林的研究发现, 大尺度的遥感数据和当 地的统计资料都低估了森林的消亡速率 (Nepstad et al ., 1999 ; Fearnside \& Barbosa , 2004)。高精度的遥 感图像则发现了当地森林密度的下降, 这可能是因 为小斑块的砍伐无法被大尺度的遥感卫星监测到。

目前，对于不同土地利用方式之间转化造成土 壤有机碳含量变化的趋势比较清楚, 但是, 这种趋势 的定量化模拟研究还很不准确。比如, 生态系统过 程模型如 TEM、IBIS、 $\mathrm{CO}_{2}$ FIX (Mohren et al . , 1990) 等, 都没有模拟土壤物理结构 (如土壤质地等) 的变 化机制。由于土壤物理结构对于土壤有机质储存及 其分解速率都有非常大的影响，因此，如果不能准确 的模拟这种变化势必影响模型对土壤碳含量变化估 测的精确度。另外, 局部生境( 如光照、温度和降雨 等)的改变也会引起土壤有机碳含量的变化, 目前的 许多模型都不能反映土地利用/覆盖变化对小气候 的反馈作用。

尽管目前存在的许多模型都耦合了能量、碳、 氮、水的生物地球化学过程, 但是, 这些模型并没有 准确地模拟土地利用/覆盖变化前后的水循环过程。 而水循环变化可能通过植物蒸散、土壤水分含量以 及水分流失速率的变化体现出来。这种水循环的变 化不仅影响局部小气候, 而且直接影响土壤有机质 的储存量和碳排放或吸收速率。因此, 土地利用/覆 盖变化过程中水循环变化的模拟应该引起特别关 注。

3.3 模型模拟的改进以及今后发展趋势

许多对土地利用/覆盖变化造成碳循环变化的 
研究都基于统计模型(比如 ,Houghton et al . , 1995， 2003 ; Fang et al . , 2001 ; Zhao \& Zhou ,2006)。由于 仅仅能观测现存的各种土地利用/覆盖类型和面积 , 而无从知道这种土地利用/覆盖类型是从哪种类型 转化而来的,所以 利用田间调查或统计资料研究土 地利用/覆盖对陆地生态系统碳循环的影响容易忽 略土地利用/覆盖类型变化的影响。如果城市面积 的增加是由农田转化而来的, 那么城市化就可能相 对减少陆地生态系统的碳释放量; 而如果是由森林 或草地转化而来, 那么城市化无疑会增加陆地生态 系统的碳释放量。同样的情况也出现在草地/森林/ 农田/湿地的转化中。从这个方面来说，遥感技术的 应用和进步以及遥感模型的出现为准确研究土地利 用/覆盖变化对陆地生态系统碳循环的影响提供了 良好的技术支持。由于遥感技术的应用和发展只局 限在最近 40 年, 遥感技术出现前以及未来的土地利 用/覆盖变化数据无法获得;并且目前利用遥感模型 直接获得的生态系统碳循环变化主要集中在小尺度 (流域以及景观尺度等) 研究, 这种高精度的遥感数 据对于生态系统的物理结构、植物年龄以及土壤和 植物的化学成分等能够进行估测，但是，该方法在大 尺度上还难以实现，有待于今后进一步改进完善。

土地利用/覆盖变化会影响整个生态系统的碳 储存及其相关过程, 如 GPP、NPP、土壤碳含量、森 林/农田产品碳、生态系统结构、土壤物理和化学性 质等 探寻土地利用/覆盖变化对生态系统碳循环的 影响，必须定量化土地利用/覆盖变化与这些过程的 关系,并且其中许多关系是动态的, 随时间和空间发 生改变。比如, 森林转化为农田后, 林产品中碳的释 放、不同深度土壤物理、化学性质的变化以及土壤碳 含量随时间的变化等。对土地利用/覆盖变化的模 拟研究需要区分两种截然不同的过程。一种是人为 引起的土地利用/覆盖类型变化, 比如, 森林和草地 变为农田或城市。这种土地利用/覆盖变化涉及到 许多人为因素, 因此, 定量化这种土地利用/覆盖变 化与生态系统碳循环过程的关系非常困难。同时由 于缺乏长期试验数据以及土地利用/覆盖变化对碳 循环的动态影响，目前所采用的簿记式方法来给每 个受影响过程设定固定参数是不合理的。许多模型 都不能模拟这种土地利用/覆盖变化对生态系统碳 循环的影响，比如 CENTURY 模型等。由于这种土 地利用/覆盖类型的变化涉及人为因素的影响 模型 的改进应从定量化人类活动 (如管理措施、林产品利 用方式等)对碳循环的影响入手, 同时结合长期试验
研究结果, 同时与遥感手段相结合, 对人类活动驱动 的土地利用变化进行更准确的估测。

另外一种是自然因素引起的土地覆盖类型的变 化, 比如, 植被演替过程中的植被覆盖变化, 自然或 人为干扰因素 (俱风、地震、火烧等) 引起的系统原 生、次生演替, 废弃农田的植被恢复等。研究这种土 地覆盖变化的影响必须首先研究土地覆盖变化对生 态系统动态结构和过程的影响。主要的生态系统植 被结构的变化包括土地覆盖变化开始后系统内植被 的定植 (Establishment)、生长发育 (Development)、繁殖 与死亡以及物种组成 (Composition)、密度和年龄结构 等。主要的动态过程包括土地利用/覆盖变化后系 统碳、氮、水等资源的循环以及能量流动等。由于这 种土地利用/覆盖变化的过程大部分受自然因素的 影响，土地覆盖变化对碳循环的影响过程相对易于 预测，因此，最近 20 年来出现了许多模拟模型。这 些模型包括基于跟踪单个个体植株动态变化的 GAP 模型，如 ,HYBRID (Friend et al . , 1993)、ED ( Ecosystem demography model) (Moorcroft et al . ,2001)、ZELIG (Urban et al . , 1993) 等, 以及跟踪系统植被动态变 化的模型，如 LPJ(Sitch et al ，，2003)、IBIS (Kucharik et al. , 2000)。GAP 模型能够用于跟踪单个植株从 定植, 生长再到死亡的整个过程, 因此, 借助此类模 型, 整个植被生态系统的结构如年龄、植物组成、密 度等将非常清楚。通过与生态系统碳、氮过程模型 耦合 (HYBRID 即为这种模型), 就可以比较准确地 估算土地利用/覆盖变化对生态系统碳循环的影响。 由于模拟生态系统每个植株个体的变化非常耗时, 输入数据难以获得, 因此, 这种 GAP 模型大都只适 用于小尺度的碳循环研究。生态系统植被动态模型 正是为了适用于大尺度模拟而对 GAP 模型进行简 化后建立的, 这种模型不再以个体为单位而是以一 个植被功能群为单位进行系统结构和过程变化的跟 踪模拟。目前,LPJ 和 IBIS 等生态系统植被动态模 型(耦合了生态系统过程模型) 已被广泛用于模拟大 尺度的生态系统碳循环 (McGuire et al , , 2001)。生 态系统过程模型与植被动态模型的耦合是目前的一 种发展趋势, 比如,Pan 等(2002) 把 TEM 模型与 LPJ 模型进行耦合 ( TEM-LPJ) 并模拟了土地利用/覆盖 变化对碳循环的影响。

由于土地利用/覆盖变化对生态系统碳循环的 影响涉及到人类活动, 因此, 土地利用/覆盖变化预 测模型 (模拟人为因素造成的土地利用/覆盖变化)、 植被动态模型 (模拟自然因素引起的自然植被覆盖 
变化)和生态系统过程模型 (模拟土地利用/覆盖变 化造成的生态系统碳、氮、水和能量过程变化)三者 的结合是未来的发展趋势。目前, 两两结合的模型 正在大量出现, 但是, 结合三种模型的综合模型有待 发展 (Tian et al., 1998a , 2005)。

\section{4 管理措施对生态系统碳循环的影响}

研究发现 地球系统存在一个未知的 碳汇”, 而 这个碳汇被认为存在于陆地生态系统中, 它可能来 源于植物生长量的增加 (Schimel, 1995 ; Keeling et al., 1996; Walker et al., 1999 ; Caspersen et al. , 2000)或土壤碳储存的增加。尽管气候变化、大气 $\mathrm{CO}_{2}$ 增加和大气氮沉降能够引起植物生长量及土壤 碳储存增加, 但是, 许多研究认为, 在土地利用/覆盖 变化过程中, 合理管理措施的应用也是主要原因之 一(Canadell , 2002 ; Houghton , 2003)。合理的管理措 施可以通过增加系统碳吸收 (比如，对人工林施肥增 加系统碳吸收)或减少系统碳损失来固定更多的碳 (比如，免耕、合理间作等减少农田土壤碳损失)。 Cole 等(1996)指出, 如果采用最佳的管理措施, 仅全 球农田土壤每年就能增加 $0.4 \sim 0.8 \mathrm{Pg} \mathrm{C}$ 的固碳量, 相当于整个全球 碳失汇” (2.9 Pg G a $\left.{ }^{-1}\right)$ 的 $20 \%$ 左 右。除了农业、林业和草地管理措施, 其它措施如湿 地保护、增加城市森林面积、荒漠地带植被保护或栽 种、适当火烧、苔原/冻土的保护等都可以增加系统 碳固定或减少碳损失。如果所有的适当管理措施都 得以实施, Metting 等 (2001) 估算整个地球系统能够 每年增加 $5.65 \sim 8.71 \mathrm{PgC}$ 的碳固定 (包括淡水生态 系统和陆地的管理) ,这远远超过目前预测的全球未 知碳汇。

\section{1 草地管理措施}

世界范围内的许多草地都存在过度利用并且管 理粗放(Oldeman, 1994)。温带草地的土壤有机质约 占世界土壤有机质的 12\%（Schlesinger，1977）, 因此， 草地管理措施的改善能够极大地影响陆地表层土壤 的有机质含量。许多研究表明, 过度放牧和粗放管 理都造成大量土壤有机质以 $\mathrm{CO}_{2}$ 的形式释放到大气 中 (Fearnside \& Barbosa, 1998; Abril \& Bucher, 1999）, 仅在美国, 由于人类对草地的粗放管理就造 成了大约 $993 \mathrm{Mg} \mathrm{C}\left(1 \mathrm{Mg}=10^{6} \mathrm{~g}\right)$ 的土壤有机碳释 放到大气中 (Kern, 1994)。在中国北部的主要放牧 区, 过度放牧、农田的开发和只放牧不管理使得草地 的退化问题非常严重, 草地生态系统的碳含量尤其 是土壤碳含量不断减少。而一系列的管理技术能够
被用于提高牧草产量,而这些管理措施同时也可能 增加土壤有机碳含量。目前, 尽管研究者开展了很 多草地退化对生态系统碳循环的小尺度试验研究, 但是，对大尺度的草地生态系统退化以及相应的管 理措施的改进对草地生态系统的碳循环影响的研究 还比较少, 有待于加强。

\section{2 森林管理}

森林的管理是增加陆地生态系统碳库的一个有 效途径。由于森林砍伐周期不断缩短, 许多人工林 都面临着土壤养分缺乏的问题，热带地区天然林是 一个比较封闭的系统, 碳、氮和水循环相对封闭, 通 常养分并不缺乏，但是由于人类对森林资源的需求 量不断增加，许多原始林都因被砍伐而变成次生林。 人类的这种干扰打破了原始林相对封闭的养分循 环，从而使原始林的生长面临着各种养分 (如氮、磷 等)限制的威胁 (Herbert et al ., 2003); 废弃农田向 森林的演替过程中, 也会出现类似养分限制问题。 因此，森林合理管理措施的采用将可能大大提高生 态系统的碳固定。许多氮沉降和林地施肥试验都证 明了这种潜力的存在 (De Vries et al . , 2006 ; Sampson et al. , 2005)。另外 其它合理的森林管理措施， 如灌溉、森林疏伐、森林杂草管理、控制性火烧、砍伐 措施以及树木栽种前的土地处理 (Site preparation) 等 都被认为能够提高森林生物量或土壤固碳量 (Johnson \& Curtis , 2001)。

\section{3 农田管理}

农田是目前人类管理最完善的生态系统, 适当 的管理措施能够增加土壤碳库, 减少土壤碳释放。 农田是减少陆地生态系统碳释放的最大潜在因素。 研究表明, 改进施肥、灌水管理措施、提高复种指数、 降低撂荒频率、合理的作物轮作、作物品种的选择 (旱地/水田)、免耕等都能够提高土壤的碳含量, 减 少农田生态系统的碳释放。但是，尽管管理措施不 断改善, 农田生态系统的土壤碳含量一般很难恢复 到以前的水平。

\section{5 结 语}

全球范围内土地利用/覆盖变化造成大量 $\mathrm{CO}_{2}$ 释放到大气中。森林砍伐、森林转化为农田或草地、 森林和草地的退化、城市用地增加等都可能导致陆 地生态系统碳释放量增加，而不同的土地利用/覆盖 变化格局造成的碳释放量不同。不同区域的土地利 用/覆盖变化对生态系统碳交换格局的影响也不一 致。统计资料的完善、遥感技术的出现与遥感数据 
分析方法的改进、以及系统模型的出现和逐步改进 等都促进了对土地利用/覆盖变化的研究, 目前, 土 地利用/覆盖变化影响碳循环的研究以模型方法为 主。由于土地利用/覆盖变化对陆地生态系统碳循 环影响广泛而复杂, 同时长期试验研究数据仍然不 足, 目前的模型预测结果还有很多不确定性。土地 利用/覆盖变化影响陆地生态系统碳循环过程的模 拟过于简化, 从而造成模型估测的结果与观测数据 差异很大, 而且, 各模型结果之间也存在较大差异。 土地利用/覆盖变化模型、植被动态模型和生态系统 过程模型的耦合是未来模型发展和改进的主要方 向。合理管理措施的应用能够显著降低土地利用/ 覆盖变化造成的碳释放量或增加陆地生态系统的固 碳量。鉴于人为因素影响的复杂性, 目前管理措施 影响生态系统碳循环的定量化研究还很少, 有待于 今后开展更多的长期试验和进一步改进管理措施影 响生态系统碳循环的定量化模拟。

\section{参考文 献}

Abril A, Bucher EH (1999). The effects of overgrazing on soil microbial community and fertility in the Chaco dry savannas of Argentina. Applied Soil Ecology, 12, 159-167.

Achard F, Eva HD, Stibig HJ, Mayaux P, Gallego J, Richards T, Malingreau JP (2002). Determination of deforestation rates of the world's humid tropical forests. Science, 297, 999-1002.

Allen RJ, Barnes DF (1985). The causes of deforestation in developing countries. Annals of the Association of American Geographers, 75, $163-184$.

Archer S, Boutton TW, Hibbard KA (2001). Trees in grasslands: biogeochemical consequences of woody plant expansion. In: Schulze D, Heimann M, Harrison S, Holland E, Lloyd J, Prentice I, Schimel D eds. Global Biogeochemical Cycles in the Climate System. Academic Press, San Diego, 115 - 138.

Archer S, Schimel DS, Holland EA (1995). Mechanisms of shrubland expansion: land use, climate, or $\mathrm{CO}_{2}$. Climatic Change, $29,91-99$.

Aselmann I, Crutzen PJ (1989). Global distribution of natural freshwater wetlands and rice paddies, their net primary productivity, seasonality and possible methane emissions. Journal of Atmospheric Chemistry, 8, 307-358.

Bolin B, Sukumar R (2000). Global perspective. In: Watson RT, Noble IR, Bolin B, Ravindranath NH, Dokken DJ eds. Land Use, Land Use Change, and Forestry. Cambridge University Press, Cambridge, UK, $23-51$.

Canadell JG (2002). Land use effects on terrestrial carbon sources and sinks. Science in China (Series C), 45 (Suppl. ), 1-9.

Caspersen JP, Pacala SW, Jenkins JC, Hurtt GC, Moorcroft PR, Birdsey RA (2000). History to carbon accumulation in U.S. forests. Science, 290, $1148-1151$.

Cerri CC, Volkoff B, Andreux F (1991). Nature and behaviour of organic matter in soils under natural forest, and after deforestation, burning and cultivation, near Manaus. Forest Ecology and Management, 38, $247-257$.

Chen GS(陈广生), Zeng DH(曾德慧), Chen FS(陈伏生), Fan ZP(范志平), Geng HD (耿海东) (2003). A research review on fertile islands" in arid and semi-arid regions. Chinese Journal of Applied Ecology (应用生态学报), 14, 2295-2300.（in Chinese with English abstract)

Chen H, Tian HQ, Liu ML, Melillo JM, Pan SF, Zhang C (2006). Effect of land-use change on terrestrial carbon dynamics in the southern USA. Journal of Environmental Quality, 35, $1533-1547$.

Cole CV, Cerri C, Minami K, Mosier A, Rosenberg N, Sauerbeck $\mathrm{P}$ (1996). Agricultural options for mitigation of greenhouse gas emissions. In: Watson RT, Zinyowera MC, Moss RH eds. Climate Change 1995: Impacts, Adaptations and Mitigation of Climate Change: Scientific-Technical Analyses. Cambridge University Press, Cambridge, $745-771$.

Crawford CS, Gosz JR (1982). Desert ecosystems: their resources in space and time. Environmental Conservation, 9, 181 - 195.

D'Antonio CM, Vitousek PM (1992). Biological invasions by exotic grasses, the grass-fire cycle, and global change. Annual Review of Ecology and Systematics, 23, 63-87.

Davidson EA, Nepstad DC, Klink C, Trumbore SE, Fisher MJ, Rao IM, Lascano CE, Sanz JI, Thomas RJ, Vera RR, Ayarza MA (1995). Pasture soils as carbon sink. Nature, 376, 472 473 .

Davidson EA, Ackerman IL (1993). Changes in soil carbon inventories following cultivation of previously untilled soils. Biogeochemistry, 20, $161-193$.

De Vries W, Reinds GJ, Gundersen P, Sterba H (2006). The impact of nitrogen deposition on carbon sequestration in European forests and forest soils. Global Change Biology, 12, 1151 1173 .

DeFries RS, Field CB, Fung I, Collartz GJ (1999) . Combining satellite data and biogeochemical models to estimate global effects of human-induced land cover change on carbon emissions and primary productivity. Global Biogeochemical Cycles, 13, 803 815 .

Detwiler RP (1986). Land use change and the global carbon cycle: the role of the tropical soils. Biogeochemistry, 2, 67-93.

Dixon RK, Brown S, Houghton RA, Trexler MC, Wisniewski J (1994). Carbon pools and flux of global forest ecosystems. Science, $263,185-190$.

Dukes JS, Mooney HA (1999). Does global change increase the success of biological invaders? Trees, 14, 135-139.

Eden MJ, Furley PA, McGregor DFM, Milliken W, Ratter JA (1991). Effect of forest clearance and burning on soil properties in northern Roraima, Brazil. Forest Ecology and Management, 
$38,283-290$.

Fan SM, Blaine TL, Sarmiento JL (1999). Terrestrial carbon sink in the Northern Hemisphere estimated from the atmospheric $\mathrm{CO}_{2}$ difference between Mauna Loa and the South Pole since 1959. Tellus, 51, 863-870.

Fang JY, Chen AP, Peng CH, Zhao SQ, Ci LJ (2001). Changes in forest biomass carbon storage in China between 1949 and 1998. Science, 22, $2320-2322$.

FAO (2005). Global Forest Resources Assessment 2005: Progress Towards Sustainable Forest Management. FAO Forestry Paper, 147.

Fearnside PM, Barbosa RI (1998). Soil carbon changes from conversion of forest to pasture in Brazilian Amazonia. Forest Ecology and Management, 108, 147 - 166.

Fearnside PM, Barbosa RI (2004). Accelerating deforestation in Brazilian Amazonia: towards answering open questions. Environmental Conservation, 31, 7-10.

Fisher MJ, Rao IM, Ayarza MA, Lascano CE, Sanz JI, Thomas RJ, Vera RR (1994). Carbon storage by introduced deep-rooted grasses in the South American savannas. Nature, 371, 236 238 .

Friend AD, Schugart HH, Running SW (1993). A physiologybased gap model of forest dynamics (HYBRID). Ecology, 74, $792-797$.

Franzluebbers AJ, Stuedemann JA, Schomberg HH, Wilkinson SR (2000). Soil organic C and N pools under long-term pasture management in the Southern Piedmont USA. Soil Biology and Biochemistry, 32, $469-478$.

GACGC (1998). The accounting of biological sinks and sources under the Kyoto Protocol: a step forwards or backwards for global environmental protection? German Advisory Council on Global Change, Special Report, Bremerhaven, 75.

Gorham E (1991). Northern peatlands: role in the carbon cycle and probable responses to climate warming. Ecological Applications, $1,182-195$.

Grover HD, Musick HB (1990). Shrubland encroachment in southern New Mexico, USA: an analysis of desertification processes in the American southwest. Climatic Change, 17, 305-330.

Guo LB, Gifford RM (2002). Soil carbon stocks and land sue change: a meta analysis. Global Change Biology, 8, 345-360.

Heal WO, Anderson JM, Swift MJ (1997). Plant litter quality and decomposition: an historical viewpoint. In: Cadisch G, Giller KE eds. Driven by Nature: Plant Litter Quality and Decomposition. CAB International, UK, $3-30$.

Herbert DA, Williams M, Rastetter EB (2003). A model analysis of $\mathrm{N}$ and $\mathrm{P}$ limitation on carbon accumulation in Amazonian secondary forest after alternate land-use abandonment. Biogeochemistry, 65, $121-150$.

Hibbard KA, Archer S, Schimel DS, Valentine DW (2001). Biogeochemical changes accompanying woody plant encroachment in a subtropical savanna. Ecology, 82, $1999-2011$.
Houghton RA, Hackler JL (2003). Sources and sinks of carbon from land-use change in China. Global Biogeochemical Cycles, 17, 1034, doi:10.1029/2002GB001970.

Houghton RA, Goodale CL (2004). Effects of land-use change on the carbon balance of terrestrial ecosystems. In: DeFries RS, Asner GP, Houghton RA eds. Ecosystems and Land Use Change. American Geophysical Union, Washington, 85-98.

Houghton RA, Hackler JL (2000). Changes in terrestrial carbon storage in the United States. I. The roles of agriculture and forestry. Global Ecology and Biogeography, 9, 125 - 144.

Houghton RA (1995) . Changes in the storage of terrestrial carbon since 1985. In: Lal R, Kimble JM, Levine E, Stewart BA eds. Soils and Global Change. CRC Lewis Publishers, Boca Raton, $45-65$.

Houghton RA (2003). Revised estimates of the annual net flux of carbon to the atmosphere from changes in land use and land management 1850-2000. Tellus, 55, 378-390.

Houghton RA, Hackler JL, Lawrence, KT (1999). The US carbon budget: contributions from land-use change. Science, 285, $574-578$.

Houghton RA, Hobbie JE, Melillo JM, Moore B, Peterson BJ, Shaver GR, Woodwell GM (1983). Changes in the carbon content of terrestrial biota and soils between 1860 and 1980: a net release of $\mathrm{CO}_{2}$ to the atmosphere. Ecological Monographs, 53, $235-262$.

Houghton RA, Skole DL, Nobre CA, Hackler JL, Lawrence KT, Chomentowski WH (2000). Annual fluxes of carbon from deforestation and regrowth in the Brazilian Amazon. Nature, 403, $301-304$.

IPCC (2000). Land use, land-use change, and forestry. In: Watson RT, Noble LR, Bolin B, Ravindranath NH, Verardo DJ, Dokken DJ eds. A Special Report of the Intergovernmental Panel on Climate Change. Cambridge University Press, Cambridge.

IPCC (2001) . A Special Report of IPCC Working Group. III. Summary for Policymakers, Emission Scenarios. Cambridge University Press, Cambridge.

Islam KR, Weil RR (2000). Land use effects on soil quality in a tropical forest ecosystem of Bangladesh. Agriculture, Ecosystems and Environment, 79, 9-16.

Jackson RB, Banner JL, Jobbagy EG, Pockman WT, Wall DH (2002). Ecosystem carbon loss with woody plant invasion of grassland. Nature, 418, 623-626.

Johnson DW (1992). Effects of forest management on soil carbon storage. Water, Air and Soil Pollution, 64, 83-120.

Johnson DW, Curtis PS (2001). Effects of forest management on soil C and N storage: meta analysis. Forest Ecology and Management, 140, $227-238$.

Johnson MP (2001). Environmental impacts of urban sprawl: a survey of the literature and proposed research agenda. Environment and Planning, 33, $717-735$.

Kasimir-Klemedtsson L, Berglund K, Martikainen P, Silvola J, 
Oenema O (1997). Greenhouse gas emissions from farmed organic soils: a review. Soil Use Management, 13, 245 - 250.

Kauppi PE, Mielikainen K, Kuusela K (1992). Biomass and carbon budget of European forests, 1971 to 1990. Science, 256, $70-74$.

Keeling CD, Chin JFS, Whorf TP (1996). Increased activity of northern vegetation inferred from atmospheric $\mathrm{CO}_{2}$ measurements. Nature, 382, 146 - 149 .

Kern JS (1994). Spatial patterns of soil organic carbon in the contiguous United States. Soil Science Society of America Journal, $58,439-455$.

Khalil MAK, Rasmussen RJ (1983). Sources, sinks and seasonal cycles of atmospheric methane. Journal of Geophysical Research, $88,5131-5144$.

King AW, Emanuel WR, Wullschleger SD, Post WM (1995). In search of the missing carbon sink: a model of terrestrial biospheric response to land-use change and atmospheric $\mathrm{CO}_{2}$. Tellus $B$, 47, $501-509$.

Kucharik CJ, Foley JA, Delire C, Fisher VA, COE MT, Lenters J, Young-Molling C, Ramankutty N, Norman JM, Gower ST (2000) . Testing the performance of a dynamic global ecosystem model: water balance, carbon balance, and vegetation structure. Global Biogeochemical Cycles, 14, 795 - 825.

Lambin EF, Turner BL II, Geist HJ, Agbola SB, Angelsen A, Bruce JW, Coomes O, Dirzo R, Fischer G, Folke C, George PS, Homewood K, Imbernon J, Leemans R, Li X, Moran EF, Mortimore M, Ramakrishnan PS, Richards JF, Skånes H, Steffen WL, Stone GD, Svedin U, Veldkamp TA, Vogel C, Xu J (2001). The causes of land use and land-cover change: moving beyond the myths. Global Environmental Change, 11, 261 269.

Levy PE, Friend AD, White A, Cannell MGR (2004). The influence of land use change on global-scale fluxes of carbon from terrestrial ecosystems. Climatic Change, 67, $185-209$.

Liu JY, Liu ML, Tian HQ, Zhuang DF, Zhang ZX, Zhang W, Tang XM, Deng XZ (2005a). Spatial and temporal patterns of China's cropland during 1990 - 2000: an analysis based on Landsat TM data. Remote Sensing of Environment, 98,442 456.

Liu JY, Tian HQ, Liu ML, Zhuang DF, Melillo JM, Zhang Z (2005b) . China's changing landscape during the 1990s: largescale land transformation estimated with satellite data. Geophysical Research Letters, 32, L02405, doi:10. 1029/2004GL021649.

Malhi Y, Grace J (2000). Tropical forests and atmospheric carbon dioxide. Trends in Ecology and Evolution, 15, 332 - 337.

Maltby E, Immirzi CP (1993). Carbon dynamics in peatlands and other wetland soils: regional and global perspectives. Chemosphere, 27, $999-1023$.

Mann LK (1986). Changes in soil carbon storage after cultivation. Soil Science, 142, $279-288$.

Matthews E, Fung I (1987). Methane emissions from natural wet- lands: global distribution, area and environmental characteristics of sources. Global Biogeochemical Cycles, 1, 61-86.

McGuire AD, Sitch S, Clein JS, Dargaville R, Esser G, Foley J, Heimann M, Joos F, Kaplan J, Kicklighter DW, Meier RA, Melillo JM, Moore B, Prentice IC, Ramankutty N, Reichenau T, Schloss A, Tian H, Williams LJ, Wittenberg U (2001). Carbon balance of the terrestrial biosphere in the twentieth century: analyses of $\mathrm{CO}_{2}$, climate and land use effects with four process-based ecosystem models. Global Biogeochemical Cycles, 15, $183-206$.

Metting FB, Smith JL, Amthor JS, Izaurralde RC (2001). Science needs and new technology for increasing soil carbon sequestration. Climatic Change, 51, $11-34$.

Ministry of Land and Resources of China (MLR) (2000, 2001, 2002, 2003) (中华人民共和国国土资源部). Annual Report on China's Land Resources. Geological Publishing House, Beijing.

Mitra S, Wassmann R, Vlek PLG (2005). An appraisal of global wetland area and its organic carbon stock. Current Science, 88, $25-35$.

Mohren GMJ, Goldewijk CGMK (1990). $\mathrm{CO}_{2}$ Fix: a Dynamic Model of the $\mathrm{CO}_{2}$-Fixation in Forest Stands. De Dorschkamp, Research Institute for Forestry and Urban Ecology. Report No. 624,35 .

Moorcroft PR, Hurtt GC, Pacala SW (2001). A method for scaling vegetation dynamics: the ecosystem demography model. Ecological Monographs, 71, $557-585$.

Murty D, Kirschbaum MF, McMurtrie RE, McGilvray H (2002). Does conversion of forest to agricultural land change soil carbon and nitrogen? A review of the literature. Global Change Biology, $8,105-123$.

Nepstad DC, Uhl C, Serrão EAS (1991). Recuperation of a degraded Amazonian landscape: forest recovery and agricultural restoration. Ambio, 20, 248-255.

Nepstad DC, Verissimo A, Alencar A, Nobre C, Lima E, Lefebvre P, Schlesinger PM, Potter C, Moutinho P, Mendoza E, Cochrane M, Brooks V (1999). Large-scale impoverishment of Amazonian forests by logging and fire. Nature, 398, $505-508$.

Oldemen LR (1994). The global extent of land degradation. In: Greenland DJ, Szabolcs I eds. Land Resilience and Sustainable Land US. CAB International, Wallingford, 99-118.

Pacala SW, Hurtt GC, Bake D (2001). Consistent Land- and atmosphere-based U. S. carbon sink estimates. Science, 292, $2316-2320$.

Pan YD, McGuire AD, Melillo JM, Kicklighter DW, Sitch S, Prentice IC (2002). A biogeochemistry-based dynamic vegetation model and its application along a moisture gradient in the continental United States. Journal of Vegetation Science, 13, 369 382 .

Parsons J (1972). Spread of African pasture grasses to the American tropics. Journal of Range Management, 25, $12-17$. 
Patterson J (1999) . Wetlands and climate change. Feasibility investigation of giving credit for conserving wetlands as carbon sinks. Wetlands International Special Publication, 1, 35.

Post WM, Kwon KC (2000). Soil carbon sequestration and landuse change: processes and potential. Global Change Biology, 6, $317-327$.

Ramankutty N, Foley JA (1999). Estimating historical changes in global land cover: croplands from 1700 to 1992. Global Biogeochemical Cycles, 13, 997 - 1027.

Reidsma P, Tekelenburg T, van den Berg M, Alkemade R (2006) . Impacts of land-use change on biodiversity: an assessment of agricultural biodiversity in the European Union. Agriculture, Ecosystems and Environment, 114, 86-102.

Sampson DA, Waring RH, Maier CA, Gough DM, Ducey MJ, Johnsen KH (2005) . Fertilization effects on forest carbon storage and exchange and net primary production; a new hybrid process model for stand management. Forest Ecology and Management, $221,91-109$.

Schimel DS (1995). Terrestrial ecosystems and the carbon cycle. Global Change Biology, 1, 77 - 91 .

Schimel DS, House JI, Hibbard KA, Bousquet P, Ciais P, Peylin P, Braswell BH, Apps MJ, Baker D, Bondeau A, Canadell J, Churkina G, Cramer W, Denning AS, Field CB, Friedlingstein P, Goodale CL, Heimann M, Houghton RA, Melillo JM, Moore BS, Murdiyarso D, Noble IR, Pacala SW, Prentice IC, Raupach MR, Rayner PJ, Scholes RJ, Steffen WL, Wirth C (2001) . Recent patterns and mechanisms of carbon exchange by terrestrial ecosystems. Nature, 414, $169-172$.

Schlesinger WH (1977). Carbon balance in terrestrial detritus. Annual Review of Ecology and Systematics, 8, 51 - 81 .

Schlesinger WH, Raikes JA, Hartley AE, Cross AF (1996). On the spatial pattern of soil nutrients in desert ecosystems. Ecology, 77, $364-374$.

Schlesinger WH, Reynolds JF, Cunningham GL, Huenneke LF, Jarrell WM, Virginia RA, Whitford WG (1990). Biological feedbacks in global desertification. Science, 247, $1043-1048$.

Scott NA, Tate KR, Bobertson JF, Giltrap DJ, Smith CT (1999) . Soil carbon storage in plantation forests and pastures: land-use change implications. Tellus, 51, 326-335.

Scott RL, Huxman TE, Williams DG, Goodrich DC (2006). Ecohydrological impacts of woody-plant encroachment: seasonal patterns of water and carbon dioxide exchange within a semiarid riparian environment. Global Change Biology, 12, $311-324$.

Sedjo RA (1992) . Temperate forest ecosystems in the global carbon cycle. Ambio, 21, 274- 277.

Serrão EAS, Falesi IC ( 1977 ). Pastagens do Trópico úmido Brasileiro. Empresa Brasileira de Pesquisa Agropecuária/Centro de Pesquisas Agro-Pecuárias do Trópico úmido (EMBRAPA/ CPATU), Belém, Pará, Brazil, 63.

Siegert F, Ruecker G, Hinrichs A, Hoffmann AA (2001). Increased damage from fires in logged forests during droughts caused by El Niño. Nature, 414, 437 - 440.

Siegenthaler U, Oeschger H (1978). Predicting future atmospheric carbon dioxide levels. Science, 199, 388 - 395 .

Sitch S, Smith B, Prentice IC, Arneth A, Bondeau A, Cramer W, Kaplan J, Levis S, Lucht W, Sykes M, Thonicke K, Venevski S (2003) . Evaluation of ecosystem dynamics, plant geography and terrestrial carbon cycling in the LPJ Dynamic Vegetation Model. Global Change Biology, 9, 161 - 185 .

Skole D, Tucker CJ (1993). Tropical deforestation and habitat fragmentation in the Amazon: satellite data from 1978 to 1988. Science, 260, $1905-1910$.

Smith DL, Johnson LC (2003) . Expansion of Juniperus virginiana L. in the Great Plains: changes in soil organic carbon dynamics. Global Biogeochemical Cycles, 17, 1062, doi: 10. 1029/ 2002 GB001990.

Tans P, Fung IP, Takahashi T (1990). Observational constraints on the global atmospheric $\mathrm{CO}_{2}$ budget. Science, 247, 1431 1438 .

Tate KR, Scott NA, Ross DJ, Parshotam A, Claydon JJ (2000). Plant effects on soil carbon storage and turnover in an adjacent forest and grassland. Australian Journal of Soil Science, 38, $685-698$.

Teixeira LB (1987) . Dinamica do Ecossistema de Pastagem Cultivada em área de Floresta na Amazônia Central. PhD dissertation, Instituto Nacional de pesquisas da Amazônia ( INPA) and Fundação Universidade do Amazonas ( FUA ), Manaus, Amazonas, Brazil, 100.

Tian HQ, Hall CAS, Qi Y (1998a) Modeling primary productivity of the terrestrial biosphere in changing environment: toward a dynamic biosphere model. Critical Reviews in Plant Sciences, 15, $541-557$.

Tian HQ, Melillo JM, Kicklighter DW, McGuire AD, Helfrich JVK, Moore B, Vörösmarty CJ (1998b). Effect of interannual climate variability on carbon storage in Amazonian ecosystems. Nature, 396, 664-667.

Tian HQ, Melillo JM, Kicklighter DW, McGuire AD, Helfrich J (1999). The sensitivity of terrestrial carbon storage to historical climate variability and atmospheric $\mathrm{CO}_{2}$ in the United States. Tellus, 51B, $414-452$.

Tian HQ, Melillo JM, Kicklighter DW, McGuire AD, Helfrich J, Moore B, Vörösmarty CJ (2000). Climatic and biotic controls on annual carbon storage in Amazonian ecosystems. Global Ecology and Biogeography, 9, $315-336$.

Tian HQ, Melillo JM, Kicklighter DW, Pan SF, Liu SY, McGuire AD, Moore B (2003). Regional carbon dynamics in monsoon Asia and its implications for the global carbon cycle. Global and Planetary Change, 37, 201 - 217, doi: 10.1016/S0921 - 8181 (02) 00205-9.

Tian HQ, Liu ML, Zhang C, Ren W, Chen GS, Xu XF (2005).

DLEM-The Dynamic Land Ecosystem Model, User Manual. the ESRA Laboratory, Auburn University, 2005. 
Turner BL II, Skole DL, Sanderson S, Fischer G, Fresco LO, Leemans R (1997). Land use and land-cover change. Earth Science Frontiers, 4, $26-33$.

Urban DL, Harmon ME, Halpern CB (1993). Potential response of Pacific north-western forests to climatic change, effects of stand age and initial composition. Climatic Change, 23, $247-266$.

Van Auken OW (2000). Shrub invasions of North American semiarid grassland. Annual Review of Ecological Systems, 31, 197 215 .

Veldkamp A, Lambin EF (2001). Predicting land-use change. Agriculture, Ecosystems and Environment, 85, 1 - 6 .

Vitousek PM, D'Antonio CM, Loope LL, Rejmanek M, Westbrooks R (1997). Introduced species: a significant component of human-caused global change. New Zealand Journal of Ecology, $21,1-16$.

Walker BH, Steffen WL, Langridge J (1999). Interactive and integrated effects of global change on terrestrial ecosystems. In: Walker BH, Steffen WL, Canadell J, Ingram JSI eds. The Ter- restrial Biosphere and Global Change, Implications for Natural and Managed Ecosystems. Cambridge University Press, Cambridge, $329-375$.

Waring RH, Running SW (1998). Forest Ecosystems: Analysis at Multiple Scales. Academic Press, San Diego, 370.

Yetman D, Burquez A (1994). Buffelgrass-Sonoran desert nightmare. Arizona Riparian Council Newsletter, 7, 8-10.

Zhang PC, Shao GF, Zhao G, Le Master DC, Parker GR, Dunning GB, Li QL (2000). China's forest policy for the 21st century. Science, 23, $2135-2136$.

Zhang S, Zhang Y, Chen J, Zhang Y, Gao Z (2004) . Temporalspatial patterns of wetlands changes in China and driving force analysis. SPIE-The International Society for Optical Engineering, 5544, 410-419.

Zhao M, Zhou GS (2006). Carbon storage of forest vegetation in China and its relationship with climatic factors. Climatic Change, 74, 175 - 189 . 